\title{
Assessment of Feminine Hygiene and Sexual Function Among Intrauterine Device Users
}

\author{
Nancy karam Youssef ${ }^{1}$, Hamida Alam ELDean Abd ELHafize ${ }^{2}$, Nadia Hussein Ahamed $^{3}$ \& Nour ELHoda \\ Mostafa Mohamed. \\ 1. Nursing Specialist, at Technical Nursing Institute, Faculty of Nursing Sohag University, Egypt. \\ 2. Assistant professor of Obstetrics and Gynecologic Nursing, Assuit University, Egypt. \\ 3. Assistant professor of Obstetrics and Gynecologic Nursing, Assuit University, Egypt. \\ 4. Assistant professor of Obstetrics and Gynecologic Nursing, Sohag University, Egypt.
}

\begin{abstract}
Background: large number of women use intrauterine device as a family planning method, and some of them complain from many problems from it, to understand the most common problems and find a solution for them, understand feminine hygiene. Aim: This study aimed to assess the feminine hygiene and sexual function among intrauterine device users. Subject and Methods: Descriptive design was used to conduct this study. Which carried out in outpatient clinics of family planning at Salama Abdulla center (west Sohag) and Agmeem hospital (East Sohage). The sample was consisting of a convenience sample of 500 women attending at those clinics their age 1845 years. Tools: Tow tools were utilized to collect data in this study Interview Questionnaire and Sexual Function Scale. Results: the result revealed that there was a highly significant correlation between vaginitis and sexual function $(\mathrm{p}=0.030 *)$, cervicitis and sexual function $(\mathrm{p}=0.024 *)$, and feminine hygiene practice and having vaginitis (P-value $=0.000 *$. Conclusion: The study revealed that there was a highly relation between having IUDs and having cervicitis, vaginitis, and sexual problems. Recommendations: family planning center should have qualified staff and sterilized equipment to put IUDs for women and teach women the good hygiene practice.
\end{abstract}

\section{Key words: Intrauterine Device, Feminine Hygiene \& Sexual Function.}

\section{Introduction}

An intrauterine device (IUD) is a small contraceptive device that is place into the uterus to prevent pregnancy. In Egypt 30\% of women using contraception chooses IUDs. Two types available the copper IUD and the hormonal IUDs (Mirena). The hormonal IUDs contains progestogen, which is a synthetic version of the hormone progesterone that women make in his body, the two types are among the most effective methods of contraception and can stay in the uterus for at least five years. (McNamee, 2019).

IUDs affect sperm movement and survival in the uterus, stopping these sperm from reaching and fertilizing the ovum .IUDs can also change the lining of the uterus (womb) to stop a fertilized ovum from sticking. The hormonal IUDs can make the fluid at the cervices to the uterus thicker, stopping sperm from getting inside the uterus. (McNamee, 2019). In addition to the benefits of IUDs, there are side effects. Some research recognize that copper IUDs may raise the risk of bacterial vaginosis and cervicitis, while others have found that IUDs can protect and enhance colonies of potentially harmful bacteria in the uterus. Many studies have found that those with copper IUDs were more likely to have. (WHO, 2019)

In some studies, women have reported a loss of libido while using the hormonal (mirena) IUD. However, it's still not clear whether IUDs have any direct effect on women sex drive, or whether this is due to other factors and causes. The IUD has strings attached so it can be removed but if the strings are left a bit long when it's inserted, it is possible that your husband will be able to feel. (Jill, 2017).

Feminine hygiene products also called menstrual hygiene products are personal care products used by women during period, vaginal discharge, and other bodily function related to the vulva and vagina these products are two types disposable or reusable. Sanitary napkins (American English) or sanitary towels (British English), tampons, and pant liners are disposable hygiene products. Menstrual cups, cloth menstrual pads and panties are the most common categories of reusable feminine hygiene products. (Nicole, et al., 2014).

Products meant to "cleanse" the area of the vulva and inside of the vagina, such as feminine deodorants, douche, feminine powders, feminine soaps, and feminine wipes have also been considered as "feminine hygiene" products. These products may cause allergic reaction and irritation as the vulva and vagina naturally flushes out bacteria. Many health professionals advise to don't using douching because it can change the balance of normal vaginal flora and acidity. (kids health, 2018).

Some women have side effects after having an IUD. They usually disappear in about 3-6 months, once your body gets used to the device in your uterus. So if 
you can stick it out for a few months, there's a well chance the side effects will ease up.. Side effects can involve: pain when the IUD is inserted, cramping or backaches for a few days after the IUD is inserted, spotting between menstruation, irregular menstruation, heavier periods and difficult menstrual cramps (Paragard), (WHO, 2019).

About 10 percent of women choose IUDs as a birth control because the risk of pregnancy is so low; However, no method of birth control is 100 percent effective. While rare, it's possible to get pregnant while using an IUD (Horsager, 2018) IUDs don't directly cause infections. If you have infection in your vagina, inserting the IUD may spread it in your uterus. Two common sexually transmitted diseases occur while having IUDs (STDs) are chlamydia and gonorrhea. That's why some doctors may want to make testing for STDs before inserting an IUDs. (Galan, 2016)

The relationship between BV and having IUD is less clear; some studies have shown an increase in the risk of BV on women using IUD' while other studies have not found any increase in risk of having the disease.

(Riggs, et al., 2007) Since the FDA approved the use of the Mirena IUD in 2000 as a birth control device, there have been increasing numbers of complaints by women who had severe signs and symptoms of bacterial vaginosis. (Dolman, 2016)

Cervicitis is a disease characterized by discharge, fluid and inflammation in the cervix, the thickened tissue and mussels that connects the uterus and the vagina and it is usually increase when using IUDs. Cervicitis is usually caused by sexually transmitted diseases, especially chlamydia and gonorrhea. (Kendrick, 2011)

Sexual function is an important issue of life for this reason; sexual dysfunction can have bad impact on the well-being of an individual. The diagnostic and statistical manual of mental disease (DSM) define that, sexual dysfunction is characterized by a disturbance in the processes that characterize the sexual response cycle or by pain during sexual intercourse. (Hubacher, et al., 2013).

In some studies, women have reported decrease or a loss of libido while using the hormonal IUD. Some women say that they feel worried that their husband will be able to feel the IUD during sexual relation, but in fact this happens too rarely. (Jill, 2017).

\section{Significance of the study}

Over all, the Egypt demographic health survey(EDHS) in 2014 reported that 59\%of currently married women in Egypt are currently using contraceptive method the most widely used method is the IUDs $30 \%$,followed by the pills $16 \%$ and injectable $9 \%$,the urban are more using contraceptive
$61 \%$ than rural 57\%, ((EL Zanaty \& way, 2014) In Mansoura University in 2011 a study conducted about rate of occurrence of vaginitis and cervicitis among IUDs users have found 12,6\% of them develop vaginitis and 8,6\% have develop cervicitis. (Ashraf, 2011).

During working in hospital with students in family planning units and obstetric and gynecological department many problems were caused by lack of hygiene and using a lot of vaginal douches, another cases want to remove IUD as it because sexual problem, and their husband complained from it, There for this study was conducted to assess feminine hygiene and sexual function among IUDs users.

\section{The aim of the study}

This study aim to assess of feminine hygiene and sexual function among IUDs users.

\section{Research question}

1- What are the methods of feminine hygiene among IUDs users?

2- Does the use of IUDs have an effect in sexual function?

\section{Subject \& methods \\ Technical design \\ Research design}

A descriptive exploratory research design was utilized in this study.

Setting: This study was carried out in outpatient clinics of family planning at Salama Abdulla family planning center at Sohag City (west Sohage) and ministry of health Akhmeem hospital (East Sohage)

Sample: convenience sample of 500 women attending at Salama Abdallahealth center in Sohage city for family planning clinic and ministry of health (Akhmeem hospital) using IUDS from 6 months to 3years Age between 18- 45 years.

Inclusion criteria: Users of intra uterine device who attending the family planning center at Sohag City and ministry of health using IUDS from 6 months to $3 y e a r s$, agree to participate in the study, age between 18- 45 years.

Tools of the study: After reviewing related literature two proper tools were used for data collection; it included:

Tool (1): Interview Questionnaire

It was divided into five parts

A - Personal data which include; patient's age, level of education, occupation and residece.

B - Menstrual history includes: age of menarche, duration, regularity interval and any menstrual abnormalities.

C - Obstetrical history which includes: numbers of pregnancy, numbers of delivery, type of delivery (normal, caesarian section) 
D - Feminine hygiene which include: vaginal douches; spray; suppository sanitary pads, kind of under wear, technique of vaginal cleaning.

E - Family Planning history which include: IUD usage duration, indications and any discomfort or complications ; metrorrhagia, spotting, infection, gastrointestinal infection, blood loss, sexual problems and unwanted pregnancy.

\section{Tool II- Sexual Function Scale}

Which include1 sexual orgasm, 2- vaginal lubrication, 3- frequency of sexual desire, 4enjoyment, 5- arousal, 6-'tense' feelings, 7- feeling 'close 8- comfortable with the husband 9- male husbands' experience of sexual problems.

Validity of tools: Tools tested for its content validity by five experts in Obstetrics and Gynecologic nursing. According to the opinions of experts the modifications were done to accommodate date wanted to be collected.

\section{Pilot study}

was carried out on $(10 \%)$ of the study sample $(n=50)$ prior to the mass distribution of the questionnaire Cronbach's alpha result for Interview Questionnaire (795) and (760) for Sexual Function Scale. no modification done in the tools , and those cases were enrolled in the final result.

Procedure: An official permission was obtained to carry out the study from Dean of faculty of nursing at the Assuit University and faculty of nursing at Sohage University. Then an official permission was obtained to collect data from outpatient clinics of family planning at Salama Abdulla family planning center at Sohag City (west Sohage) and ministry of health Akhmeem hospital (East Sohage). Data collection procedure was conducted in over 8 months The researcher was available in the study settings 3 days per week in each study setting from 9 Am to 1 Pm. Data collection from women, who accepted to be included in the study after explaining the aim of the study, the interview of every women take 10 minutes. Every question was explained to every case and his answers were clarifying. Some cases chosen to answer the questionnaire alone without assistance from the researcher. Then after investigator finished all data collection, the investigator asked the women about any question to clarify it and emphasizing each women problems how to deal with it. Analyses were conducting by using SPSS 20.0 software. Limitation of the study: According to culture, some women refused to speak in sexual issues and sometimes data which obtained is not true that related to this issue.

- Some women refused to answer questions related to sexual status because their husband with them.

- Some women asked if i married or not before answer questions related to sexual status.
- Some women answer all questions except questions related to sexual status, and these cases excluded from the study

Ethical consideration

Research proposal was approved from Ethical Committee in the faculty of nursing, Assuit University, oral consent was obtained from women that are could be intended to participate in the study, after explaining the nature and purpose of the study, confidentiality and anonymity would be assured, participants had been the right to refuse or participate from the study without any rational, participants privacy was considered during collection of data. Also, approval from the ethical committee of the Egyptian Ministry of health was given to the researcher.

\section{Statistical design}

Upon completion of data collection, the data were scored, tabulated, and analyzed through data entry and analysis by computer using the "Statistical Package for Social Science" (SPSS) version 20. Data were presented using descriptive statistics in the form of percentages, frequency mean and standard deviation. Inferential statistical tests of significance such as Pearson correlation, and independent t-test were used to identify group differences and the relations among the study variables. The $\mathrm{p}$ value > 0.05 indicates non-significant result while, the $p$ value $<0.05$ is significant and the $p$ value $\leq 0.01$ is highly significant. 


\section{Results}

Table (1): distribution of the study subjects according to their socio-demographic characteristics $(N=500)$.

\begin{tabular}{|l|c|c|}
\hline & No. (500) & \% \\
\hline Age: (years) & & 20.0 \\
\hline $18-<25$ & 100 & 43.8 \\
\hline $25-<35$ & 219 & 36.2 \\
\hline $35-45$ & 181 & \\
\hline Mean \pm SD & $34.19 \pm 8.54$ & 47.6 \\
\hline Place of residence & & 52.4 \\
\hline Rural & 238 & 11.6 \\
\hline Urban & 262 & 7.0 \\
\hline Level of education & & 11.2 \\
\hline Illiterate & 58 & 43.0 \\
\hline Read \& write & 35 & 24.0 \\
\hline Basic education & 56 & 3.2 \\
\hline Secondary & 215 & \\
\hline University & 120 & 64.2 \\
\hline Postgraduate & 16 & 35.8 \\
\hline Working status & & \\
\hline Housewife & 321 & \\
\hline Employee & 179 & \\
\hline
\end{tabular}

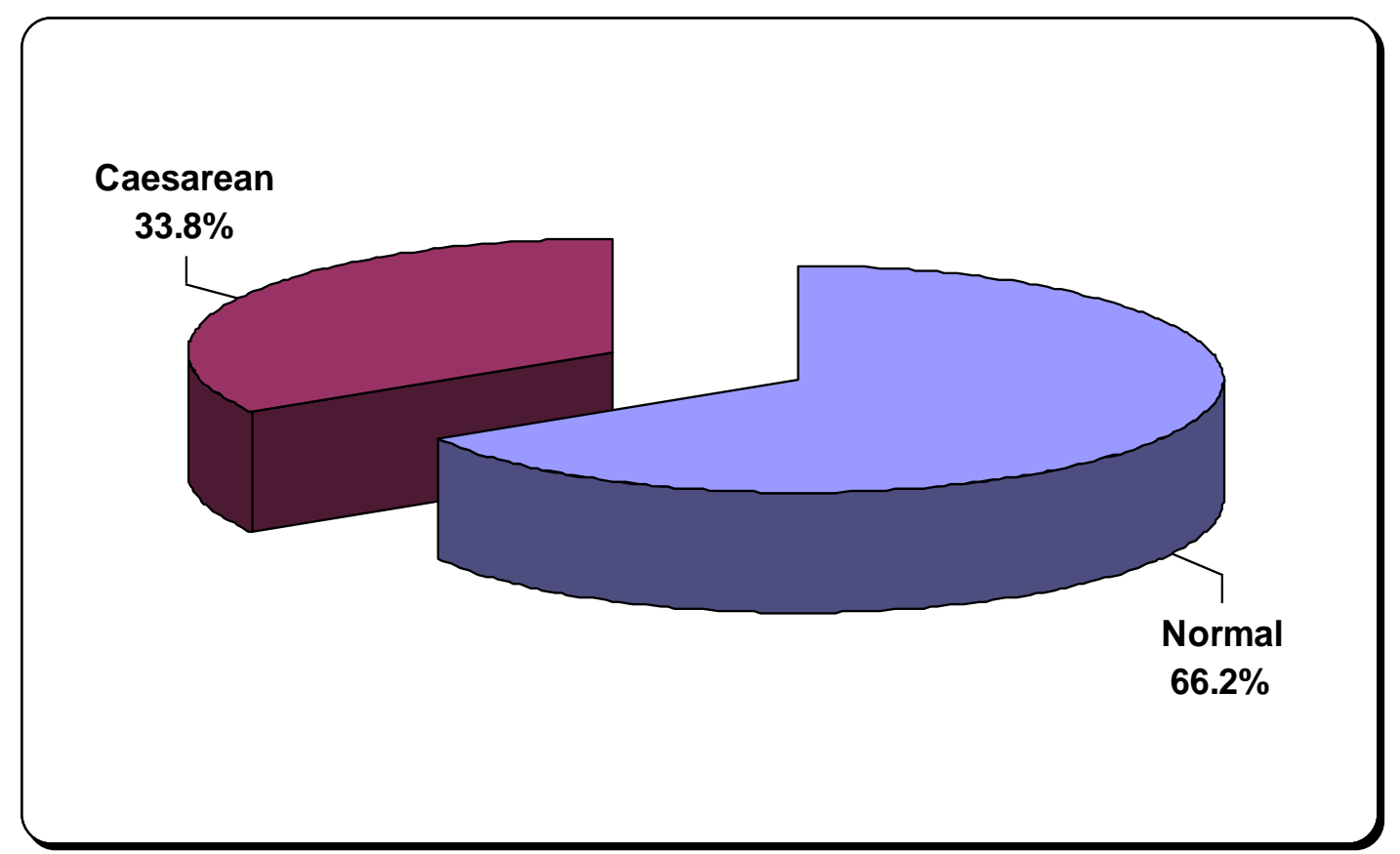

Figure (1): distribution of study subjects according to Mode of delivery. 
Table (2): distribution of the study sample according to Feminine hygiene and method of cleaning.

\begin{tabular}{|l|c|c|}
\hline & No. (500) & \% \\
\hline Feminine hygiene & & 45.8 \\
\hline Wash vagina with hot water only & 229 & 22.6 \\
\hline Wash vagina with cold water only & 113 & 30.6 \\
\hline Wash vagina using water + disinfectant & 153 & 1.0 \\
\hline Use of vaginal suppository & 5 & \\
\hline Types of sanitary pads & & 21.8 \\
\hline Cotton & 109 & 78.2 \\
\hline Sanitary napkins & 391 & \\
\hline Types of underwear & & 47.6 \\
\hline Cotton & 238 & 52.4 \\
\hline Synthetic fibers & 262 & \\
\hline Method of cleaning the vagina & & 60.2 \\
\hline External cleaning by hand & 301 & 2.4 \\
\hline External cleaning by hand with the use of gloves & 12 & 37.4 \\
\hline Cleaning by inserting fingers in to vagina & 187 & \\
\hline How to clean vulva & & 68.2 \\
\hline From front to back & 341 & 31.8 \\
\hline From back to front & 159 & \\
\hline
\end{tabular}

Table (3):distribution of the study subjucts about Pattern of cervicitis and vaginitis.

\begin{tabular}{|l|c|c|}
\hline \multicolumn{1}{|l|}{} & No. (500) & \% \\
\hline Vaginitis: & & 47.6 \\
\hline Yes & 238 & 52.4 \\
\hline No & 262 & \\
\hline Pattern of vaginitis: & & 16.4 \\
\hline External redness & 39 & 17.2 \\
\hline External redness + secretions & 41 & 66.4 \\
\hline Redness + secretions + itching & 158 & 29.8 \\
\hline Cervicitis: & & 70.2 \\
\hline Yes & 149 & \\
\hline No & 351 & 46.3 \\
\hline Pattern of Cervicitis : & & 23.5 \\
\hline Secretions + pain with intercourse & 69 & 57.0 \\
\hline There are bloody secretions after intercourse & 35 & \\
\hline Secretion + pain in symphysis pubis + pain in the back & 85 & \\
\hline
\end{tabular}

Table (4): Distribution of the subjects according to vaginitis in relation to methods of vulva cleaning.

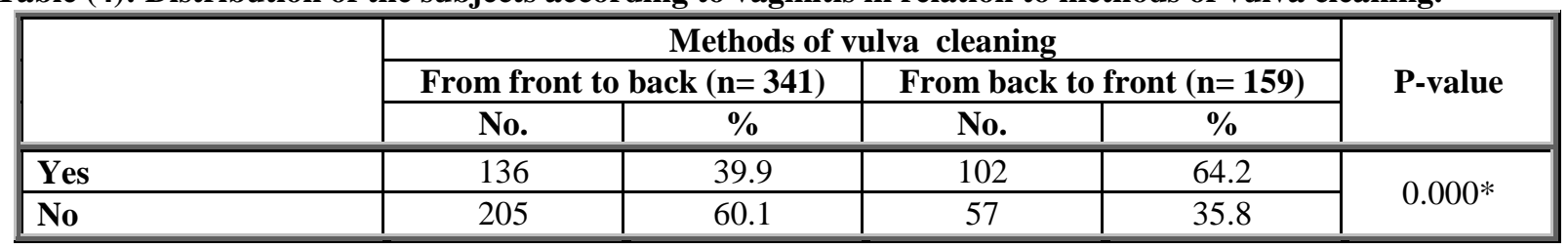


Table (5): Distribution of the study subjects according to sexual function and vaginitis.

\begin{tabular}{|l|c|c|c|c|c|}
\hline \multirow{2}{*}{} & \multicolumn{3}{|c|}{ Vaginitis } & \multirow{2}{*}{ P-value } \\
\cline { 2 - 5 } & No. & $\%$ & No. & $\%$ & \\
\cline { 2 - 5 } & & & & \\
\hline
\end{tabular}

Table (6): Distribution of the study subjects according to sexual function and cervicitis.

\begin{tabular}{|c|c|c|c|c|c|}
\hline & \multicolumn{4}{|c|}{ Cervicitis } & \multirow{3}{*}{ P-value } \\
\hline & \multicolumn{2}{|c|}{ Yes } & \multicolumn{2}{|c|}{ No } & \\
\hline & No. & $\%$ & No. & $\%$ & \\
\hline \multicolumn{5}{|c|}{ Difference in libido after using of IUD } & \multirow{3}{*}{0.869} \\
\hline Yes & 38 & 25.5 & 92 & 26.2 & \\
\hline No & 111 & 74.5 & 259 & 73.8 & \\
\hline \multicolumn{5}{|c|}{ Difference in the sexual desire of the husband after using of IUD } & \multirow{3}{*}{0.698} \\
\hline Yes & 37 & 24.8 & 93 & 26.5 & \\
\hline No & 112 & 75.2 & 258 & 73.5 & \\
\hline \multicolumn{5}{|c|}{ Vagina easily become wet during sexual intercourse } & \multirow{3}{*}{$0.024 *$} \\
\hline Yes & 108 & 72.5 & 286 & 81.5 & \\
\hline No & 41 & 27.5 & 65 & 18.5 & \\
\hline \multicolumn{5}{|c|}{ Easily reach orgasm: } & \multirow{3}{*}{$0.024 *$} \\
\hline Yes & 108 & 72.5 & 286 & 81.5 & \\
\hline No & 41 & 27.5 & 65 & 18.5 & \\
\hline \multicolumn{5}{|c|}{ Satisfied at the end of the sexual relationship } & \multirow{3}{*}{0.078} \\
\hline Yes & 112 & 75.2 & 288 & 82.1 & \\
\hline No & 37 & 24.8 & 63 & 17.9 & \\
\hline
\end{tabular}




\begin{tabular}{|c|c|c|c|c|c|}
\hline & \multicolumn{4}{|c|}{ Cervicitis } & \multirow{3}{*}{ P-value } \\
\hline & \multicolumn{2}{|c|}{ Yes } & \multicolumn{2}{|c|}{ No } & \\
\hline & No. & $\%$ & No. & $\%$ & \\
\hline \multicolumn{5}{|c|}{ Husband satisfied at the end of the sexual relationship } & \multirow{3}{*}{0.954} \\
\hline Yes & 110 & 73.8 & 260 & 74.1 & \\
\hline No & 39 & 26.2 & 91 & 25.9 & \\
\hline \multicolumn{5}{|c|}{ Feel uncomfortable or pain during a sexual relationship } & \multirow{3}{*}{$0.000 *$} \\
\hline Yes & 66 & 44.3 & 63 & 17.9 & \\
\hline No & 83 & 55.7 & 288 & 82.1 & \\
\hline \multicolumn{5}{|c|}{ Problems with the husband } & \multirow{3}{*}{$0.041^{*}$} \\
\hline Yes & 12 & 8.1 & 13 & 3.7 & \\
\hline No & 137 & 91.9 & 338 & 96.3 & \\
\hline \multicolumn{5}{|c|}{ Have infections } & \multirow{3}{*}{$0.000^{*}$} \\
\hline Yes & 126 & 84.6 & 92 & 26.2 & \\
\hline No & 23 & 15.4 & 259 & 73.8 & \\
\hline
\end{tabular}

Table (1): Demonstrates mean age of cases was34.19 \pm 8.54 nearly half of cases aged $25-<35$ and nearly tow third of them was housewife and $43 \%$ were had secondary education.

Fig (1): Distribution of the study subjects according to mode of delivery $(66,2 \%)$ of them had normal delivery, $(33,8 \%)$ had cesarean section.

Table (2): Demonstrates at nearly half of cases $(45,8 \%)$ was Wash vagina with hot water only $(60,2 \%)$ use External cleaning by hand, $(68,2 \%)$ clean vulva From front to back ,(78,2\%)of them used Sanitary napkins, $(52,4 \%)$ used Synthetic fibers under wears.

Table (3) Demonstrates that $(47,6 \%)$ of cases had vaginitis and the more complain from vaginitis was Redness + secretions + itching $(66,4 \%)$ and $(29,8 \%)$ of cases had cervicitis and the more complain from it was Secretion + pain in symphysis pubis + pain in the back $(57 \%)$.

Table (4): Show that there is highly significance between vaginitis and cleaning vulva from back to front number of cases who clean vulva from back to front was $(31,8 \%),(64 \%)$ of them having vaginitis $\mathrm{p}$ value $\left(0.000^{*}\right)$

Table (5): Demonstrates that $238(46,6 \%)$ of cases had vaginitis $(30,3 \%)$ of them feel uncomfortable or pain during sexual relation, 262 hadn't vaginitis $(52,4 \%),(21,8 \%)$ of them feel uncomfortable or pain during sexual relation

Table (6): Demonstrated that $149(29,8 \%)$ of cases had cervicitis $(44,1 \%)$ of them feel uncomfortable or pain during sexual relation, $351(70,2 \%)$ of cases had not cervicitis $(17,9 \%)$ of them feel uncomfortable or pain during sexual relation.

\section{Discussion}

IUDs is one of the most family planning method used worldwide and in Egypt, during working in family planning units founded that many women prefer to use it even if it can cause problems

of them such as menorrhagia, infection and sexual problems

There are five types of IUDs all work roughly the same way: They thicken cervical mucus so sperm can't enter the uterus to fertilize an egg. (Either copper or synthetic progesterone) makes it more difficult for them to travel through the uterus and tubes toward an egg. (Rinkunas, 2016)

Present study showed that women who were used IUD nearly half of them aged around 25-35 year, with mean age was34.19 \pm 8.54 This finding was supported by the finding of Wright (2014), their study was "Cervical Ectropion \& Intra-Uterine Contraceptive Device" (IUCD) A 5-year retrospective study was conducted by assessing existing clinic records from years 2007-2011.they found that Clients with IUDs undergo routine pelvic examination during check-up visits. A total of 628 clients the mean age of the IUCD users were $34.7 \pm 6.52$ years. On the other hand, this finding not supported by the finding of Koseoglu (2016) their study was" Is There Any Impact of Copper Intrauterine Device on Female Sexual Functioning?" This cross-sectional study was conducted between June 2015 and January 2016 at Mugla Sitki Kocman University, Department of Obstetrics and Gynecology Unit In this cross-sectional study subjects were divided into two groups. Study groups consisted of 92 IUD-users mean age of them was $(5.1 \pm 1.2$ years). From the researcher point of view this difference because the sample size was small.

As Regard to education the present study showed that nearly half of cases have secondary education, this finding was supported by the finding of Wright (2014), this study titled was "Cervical Ectropion and Intra-Uterine Contraceptive Device (IUCD)" 517 
(82.3\%)of cases had secondary education. From the researcher point of view this similarity as education becomes basic need in all different social layers.

In this current study reported that half of cases get their menarche was (13-14) and with duration (3-5) days, this study is supported by Koseoglu (2016) this study title was" Is There Any Impact of Copper Intrauterine Device on Female Sexual Functioning" In this cross-sectional study subjects were divided into two groups IUD users group was nearly half and control group was nearly half. Both two gropes started their menarche between age (12-14) years with duration (3-5) days.

In this study found that women in her feminine hygiene wash vagina with hot water only were nearly half of all cases and this because their little knowledge about practices of cleaning We found three quarter of cases using sanitary napkins than cotton because as they are more effective than cotton Regarding vaginitis found one quarter of cases have vaginitis. Sackley (2018) this study title was" Could an IUD Alter the Vaginal Microbiome?" founded that those with copper IUDs were more likely to experience bacterial vaginosis half of patients with a copper IUD had bacterial vaginosis People who used copper IUDs for over a year were also significantly more likely to have Mycoplasma and yeast infections. On the other hand, this finding not supported by the finding of Kaliterna (2011) it is title was" An intrauterine device as a possible cause of change in the microbial flora of the female genital system" They conduct survey included 236 women of fertile age from gynecological practices in the area of Split and Dalmatia County, Croatia. The subjects were divided into two groups: IUD users and a control group (women not using any contraception methods). The most frequently isolated bacteria in both groups were Escherichia coli and Urea plasma urealyticum with significantly higher rates in IUD users ( $\mathrm{P}<$ 0.001). Both colonization and infection had higher rates in IUD users $(\mathrm{P}<0.001)$. There were no significant differences either in the frequency of bacteria isolation regarding different IUD types $(\mathrm{P}=$ $0.93)$, or in relation to duration of IUD use $(\mathrm{P}=$ 0.67).from the researcher point of view lack of family planning units sterilization and equipment to put IUDs.in European counters females have high degree of cleaning and interest to this part of their body, and so infection not connected whit having IUD or not.

Regarding cervicitis in present study found one third of cases had cervicitis This result was not supported by Wright (2014) "Cervical Ectropion and IntraUterine Contraceptive Device (IUCD)" found that seventy-nine clients $(12.6 \%)$ had cervicitis. from the researcher point of view increase percent of cervicitis in present study due to lack of hygiene practice of subjects .

Regarding vaginitis and sexual function found cases had vaginitis had difference in libido ( $p$-value 0,160 ), difference in sexual desire of husband ( $\mathrm{p}$-value $0,108)$, feel un comfortable or pain during relation ( $\mathrm{p}$ value 0,030) This result was supported by Gordon (2016)" High prevalence of sexual dysfunction in a vulvovaginal specialty clinic cases" study evaluated the presence and predictors of sexual dysfunction in a vulvovaginal enrolled 161 women, aged 18-80 years (median $=36$ ), presenting with vulvovaginal complaints131 women (three quarter of subjects) reported chronic symptoms86 (half) women experienced sexual dysfunction, Sexual dysfunction is present in over half of women presenting to a vulvovaginitis referral clinic. From the researcher point of view this percent because swelling and inflammation in vaginal wall cause dyspareunia and lack of comfortable during relation.

Regarding cervicitis and sexual function found those had cervicitis had sexual problem $(31,1 \%)$ difference in libido (p-value 0,869$)(74,5 \%)$, this agree with study by Ma, et al., (2015)"Female Sexual Dysfunction in Women with Non-Malignant Cervical Diseases" A Study from an Urban Chinese Sample " Hospital of Nanjing Medical University, found that women with cervicitis higher prevalence of sexual problem $(51.8 \%$ vs. $34.8 \%$ ), compared with the control group. From the researcher point of this percent because swelling and inflammation in vaginal wall cause dyspareunia and lack of comfortable during relation.

\section{Conclusion \& Recommendation}

Overall, the study concluded that:

Based on the finding of the study, it can be concluded that many problems occur by IUDs method, such as vaginitis $(47,6 \%)$ cases, cervicitis $(29,8 \%)$ and sexual problems $(31,1 \%)$. Feminine hygiene affected women's health and contributing to make sexual problem .

\section{Recommendations}

- Developing in service training program for nurses regarding problems occur with IUDs and how to manage it, and the best method of feminine hygiene

- Raise awareness of nurses on family planning services.

- Well-equipped of family planning units with guidelines about feminine hygiene, trained nurses and sterilized equipment.

- Feminine hygiene guidelines are explained and discuses for women coming to outpatient clinics. 
Repeat this research on a large sample size and different governmental hospitals for generalization.

\section{Reference}

1. Ashraf A., (2011) cercicitis and vaginitis while using IUDs Facultyof Medicine, Mansoura University, Troil, Mansoura, Egypt https:// www.google.com.eg/web

2. Dolman Law Firm, (2016): Did My Mirena IUD Cause Bacterial Vaginosis? Journal of Environmental and Public Health available at https://newportricheyinjury.wordpress.com/201 6/04/18/did-my-mirena-iud-cause-bacterialvaginosis/.

3. El Zanaty F., \& Way A., (2014): Family planning Egypt demographic and health survey Cairo Egypt. Ministry of Health and Population, National Population Council, El-Zanaty and Associates

4. Galan, G., (2016) Birth control method and infection 2016,Health line Journal of lower genital tract diseases available at https://www.healthline.com/health/birthcontrol/iud-

5. Gordon, D., Gardella, C., Eschenbach, D., \& Mitchell, C., (2016): High prevalence of sexual dysfunction in a vulvovaginal specialty clinic. Journal of lower genital tract disease, 20(1), 80

6. Horsager, R., Boehrer, M., (2018): What happens if I get pregnant with an IUD? You're Pregnancy Matters available at https://utswmed.org/medblog/pregnancy-iud/.

7. Hubacher, D., Grimes, D., \& GemzellDanielsson, K., (2013): Pitfalls of research linking the intrauterine device to pelvic inflammatory disease. Obstetrics \& Gynecology, 121(5), 1091-1098.

8. Jill, D., (2017): Ask a GP: Can an IUD affect my libido?, News Corp Australia, Body +soul, Available at https://www. Body and soul.com .au/health/ask-a-gp-can-an-iud-affect-mylibido/newsstory/538b0debbdff3fa59d1b7cd210bced00

9. Kendrick (2011): Diseases Characterized by Urethritis and Cervicitis, Center of disease control and prevention, available at https://www.cdc.gov/std/treatment/2010/urethrit is-and-cervicitis.htm

10. Kids health organization (2018): Menstrual_ hygiene_products "Feeling Fresh" Journal of Environmental and Public Health.. Available at https://en.wikipedia.org/wiki/Feminine_hygiene

11. Koseoglu, S., Deveer, R., Akin, M., Gurbuz, A., Kasap, B., \& Guvey, H., (2016): Is There Any Impact of Copper Intrauterine Device on
Female Sexual Functioning?. Journal of clinical and diagnostic research: JCDR, 10(10), QC21.

12. Ma, J., Kan, Y., Zhang, A., Lei, Y., Yang, B., Li, P., \& Pan, L., (2015): Female sexual dysfunction in women with non-malignant cervical diseases: A study from an urban Chinese sample. PloS one, 10(10), e0141004.

13. Mcnamee, K., (2019): Intrauterine Device (IUD) Contraception, family planning victoria ,reproductive and sexual health, available at https://www.fpv.org.au/for-

you/contraception/long-acting-reversiblecontraception-larc/iud-contraception-intrauterine-device.

14. Nicole, W., (2014): A question for women's health: chemicals in feminine hygiene products and personal lubricants. Environmental Health Perspectives. 122 (3): $\quad$ A70A75. doi:10.1289/ehp.122A70. PMC 3948026. PMID 24583634

15. Riggs, M., Klebanoff, M., Nansel, T., Zhang, J., Schwebke, J., \& Andrews, W., (2007): Longitudinal association between hormonal contraceptives and bacterial vaginosis in women of reproductive age. Sexually transmitted diseases, 34(12), 954-959.

16. Sackley, (2018): Could an IUD Alter the Vaginal Microbiome?,U Bimo Avilable at https://ubiome.com/blog/post/iud-alter-vaginalmicrobiome/

17. WHO, (2019): Could an IUD Alter the Vaginal Microbiome? Biome journal, available at https://ubiome.com/blog/post/iud-alter-vaginalmicrobiome/

18. WHO, (2019): Planned Parenthood, what are the disadvantages of IUDs? Federation of America Inc. available at https://www .planned parenthood.org/learn/birth-control/iud/what-arethe-disadvantages-of-iuds

19. Wright, K., Mohammed, A., Salisu-Olatunji, O., \& Kuyinu, Y., (2014): Cervical Ectropion and Intra-Uterine Contraceptive Device (IUCD): a five-year retrospective study of family planning clients of a tertiary health institution in Lagos Nigeria. BMC research notes, 7(1), 946. 